\title{
К.А. Мачин
}

\section{ОБУЧЕНИЕ В ТЕЧЕНИЕ ВСЕЙ ЖИЗНИ, ПРОФЕССИОНАЛЬНАЯ МОБИЛЬНОСТЬ И ЭФФЕКТИВНАЯ ЗАРАБОТНАЯ ПЛАТА НА РЫНКЕ ТРУДА}

\begin{abstract}
Современное динамично развивающееся общество предъявляет новые повыменные требования к способностям и усилиям работников предприятия. Это, в свою очередь, определяет точки соприкосновения экономических интересов работников и работодателей. Предприятия стремятся к максимизаџии своей прибыли, а работники максимизируют индивидуальную полезность. Столкновение этих иелей эффективно регулируется рыночным механизмом на основе формирования эффективной заработной платы. Основной целью авторского исследования является формирование экономического механизма профессиональной мобильности на основе моделирования решений о эффективной заработной плате.

Ключевые слова: обучение в течение всей жизни, профессиональная мобильность, эффективная заработная плата, неконкурируюшие группы, усилия работника, эффективность труда, безработиияа.
\end{abstract}

Современное общество представляет собой динамично развивающуюся социально-экономическую систему. Такая динамика, имеющая непосредственное отношение к деятельности людей, как нельзя ярче отражается на их профессиональных способностях. Для поддержания столь интенсивного развития в современных условиях индивидам требуется профессиональная гибкость и адаптивность, которые обеспечиваются на основе мобильности. Профессиональная мобильность как экономическое явление подчиняется определенным закономерностям Economics. C экономической точки зрения основными переменными решений о профессиональной мобильности являются: эффективная заработная плата, численность различных профессиональных групп и их наполненность, а также структура производства территории. В зависимости от исходной ситуации, определяемой экономическими предпосылками формирования структуры отраслей экономики на данной территории и стадией экономического цикла, происходит формирование локальных равновесных значений эффективной заработной платы в различных профгруппах. Данные локальные значения по профгруппам определяют в итоге общее экономическое равновесие на рынке труда.

В 70-е гг. XIX в. под влиянием научных трудов ирландского экономиста Дж. Кернса формируется концепция неконкурирующих профессиональных групп. Он вводит термин «неконкурирующие группы», применяемый для широкого круга профессиональных категорий: ремесленников, торговцов, специалистов и др. Дж. Кернс описывает барьеры для вхождения в профессиональную группу и перемещения между ними, на основе которых делает вывод о том, что на общем рынке труда конкуренция между работниками разных профессий невозможна [1]. Дж. Милль поддержал эту идею 
Дж. Кернса, подчеркивая, что различия между группами были очень значительны и напоминали наследственное разделение на касты [2]. Тем не менее Дж. Милль назвал основным источником появления возможной мобильности образование и обучение [2].

В начале XX в. интерес к данной теории уменьшился, технологические изменения и рост массового производства привели к снижению барьеров между профгруппами рабочих. После Второй мировой войны проблемы рынка труда профгрупп вновь стали особенно актуальны. По мнению ряда ученых T. Dunlop [3], G. Lewis [4], B. Hirsch, J. Addison [5], появление такого института, как профсоюзы, стало активно влиять на параметры неконкурентных элементов рынка труда и формирование заработной платы. А по мнению C. Kerr [6], A. Ross [7], L. Reynolds [8], это привело к балканизации рынка труда, контролю и даже регулированию вхождения в профессию со стороны профсоюзов.

В 1970-е гг. проблемы, связанные с концепцией неконкурирующих групп, расширились. Появились новые барьеры для профессиональной мобильности, такие как дискриминация по полу и расе. F. Blau и L. Kahn [9] выявили устойчивую дифференциацию в доходах групп, разделенных по половому и расовому признакам. Это вызвало развитие теорий P. Doeringer [10], W. Darity, P. Mason [11] о сегментации рынка труда. В это же время появляются теории внутрифирменной профессиональной мобильности таких ученых, как T. Dunlop [3], O. Williamson [12], согласно которым профессиональная мобильность возможна внутри одной фирмы и проблематична в ситуации перехода работников из одной фирмы в другую при одновременной смене профгруппы. Такая внутрифирменная мобильность отчасти способствует повышению эффективности внешних по отношению к фирме рынков труда.

В конце 1980-х появляется теория эффективной заработной платы. Над ее созданием и развитием трудились Д. Стиглиц, G. Akerlof [13], L. Katz [14], L. Summers [15], J. Yellen [16], R. Solow [17], K. Lang, J. Leonard [18]. Теория эффективной заработной платы предполагает, что для повышения эффективности труда и усилий работника, а также для снижения уклонений работника ему необходимо платить высокую заработную плату. Динамика эффективной заработной платы согласно данной концепции приводит к прямо пропорциональной динамике в усилиях работника. В ситуации получения работником эффективной заработной платы угроза увольнения будет более существенным мотивом для повышения эффективности труда и ликвидации «отлыниваний» от работы. В отношении неконкурирующих групп эффективная заработная плата, по мнению автора, должна регулировать профессиональную мобильность и перемещение работников из одной профгруппы в другую посредством обучения в течение всей жизни (Lifelong learning).

Концепция обучения в течение всей жизни возникла благодаря появлению информационного общества и экономики, основанной на знаниях. Концепция экономики, основанной на знаниях, появилась в 1960-е гг. в трудах R.E. Lane как направление социологических исследований. Но свое полноценное развитие она получила в 1990-е гг. в исследованиях D. Dikson, $\mathrm{N}$. Stehr и документах Организации экономического сотрудничества и развития (ОЭСР). Активному развитию концепции способствовали сложившиеся 
экономические реалии: неравновесная динамика рынков, глобализация, повышение скорости возникновения инноваций, стремительное развитие информационных технологий, быстрое обновление знаний и т.д. Все это привело в ЕС к разработке Меморандума ЕС по образованию в течение всей жизни, где в долгосрочной перспективе были поставлены проблемы развития образования, а также было проведено исследование ОЭСР в рамках программы «PISA» (Программа исследования качества образования в мире). Экономика, основанная на знаниях, потребовала наличия эффективной широко охватывающей все слои населения системы образования и обучения, способствующих росту численности высококвалифицированных специалистов в составе рабочей силы, создающих благоприятные условия для непрерывного образования в течение всей жизни.

Впервые концепция обучения в течение всей жизни (Lifelong learning LLL-концепция) упоминается в докладе Комиссии Э. Фора в 1972 г., подготовленном под эгидой ЮНЕСКО. В этом докладе Э. Фор говорит о том, что обучение и образование людей в своей эволюции перешли от врожденной способности к обучению как социальной функции индивидов до институционально оформленной сферы просвещения и приобретения профессиональных знаний и навыков. В условиях современной глобализации в мире экономики, основанной на знаниях, и динамики информационного общества важно сохранять постоянную актуальность знаний работников, что возможно лишь на основе обучения в течение всей жизни [19]. В рамках LLL-концепции выделяются три вида обучения: формальное в образовательных организациях с присвоением дипломов и свидетельств, неформальное - на производстве или через обмен опытом с коллегами и самообучение.

В 1996 г. возобновляется интерес к концепции обучения в течение всей жизни. В докладе Ж. Делора на Международной комиссии по образованию в XXI в. отмечается, что, несмотря на возрастание и обострение противоречий в современном обществе, именно просвещение в рамках концепции обучения в течение всей жизни будет одним из ключей к решению проблем нового века. Ж. Делор отмечает также, что во главе образования должны лежать четыре основополагающих принципа: учиться жить, учиться познавать, учиться делать и учиться сосуществовать [20]. Концепция обучения в течение всей жизни активно реализуется на Западе как явная парадигма с развернутой институциональной средой. В России понимание необходимости обучения в течение всей жизни носит неявный характер, а стимулы к некоторой актуализации и расширению знаний и навыков посредством обучения диктуются рыночным механизмом и экономической динамикой и воспринимаются далеко не всем персоналом организаций и фирм.

Обучение в течение всей жизни требует постоянной оценки и мониторинга наиболее актуальных и требуемых рынком знаний (в широком смысле). Требуемые рынком знания могут составлять систему компетенций профессии, которой работник в данный (текущий) момент не обладает. Это вызывает необходимость смены текущей профессии или существенного расширения ее функций и способствует развитию профессиональной мобильности работников. Под профессиональной мобильностью здесь следует понимать образовательное расширение профессиональных функций работника, позволяющих 
ему переходить из одной профессиональной группы в другую, происходящее под воздействием стимулов сложившихся на рынках благ, труда и капитала.

В современных российских условиях профессиональная мобильность является актуальным фактором динамики на рынке труда. По словам К.Э. Лайкам, заместителя руководителя Росстата РФ, в России «работает не по специальности - почти 60 процентов» [21] занятого населения. Таким образом, можно констатировать наличие в нашей стране огромного потенциала профессиональной мобильности.

В такой ситуации как у фирм, так и у работников возникает проблема определения оптимальной стратегии поведения на рынке труда для формирования эффективной заработной платы и максимизации своих целевых функций. Для объяснения механизма профессиональной мобильности на рынке труда и установления эффективной заработной платы в условиях конкуренции между работниками разных профгрупп воспользуемся классическими предпосылками вслед за R. Solow, L. Katz, L. Summers и D. Romer [22]. Пусть в экономике существуют только репрезентативные фирмы, стремящиеся максимизировать свою целевую функцию прибыли ( $\pi)$, имеющую вид

$$
\pi=\max _{L, w}(F(e L)-w L)
$$

где $F(e L)$ - выпуск фирмы; $w$ - реальная заработная плата, которую она платит работнику; $e$ - усилия работника; $L$ - количество нанимаемого фирмой труда работников, не эластично предлагающих каждый одну единицу труда.

В данном случае выпуск фирмы $(F)$ зависит от двух переменных: усилий работника и числа нанимаемых работников. Пренебрегая остальными факторами, будем предполагать, что производственная функция зависит от произведения количества труда на интенсивность усилий.

Пусть для выпуска репрезентативной фирмы выполняются условия:

$$
F^{\prime}(e L)>0, F^{\prime \prime}(e L)<0
$$

В условиях профессиональной мобильности работников функция усилий (e) будет зависеть от заработной платы на текущем рабочем месте, заработной платы на аналогичном рабочем месте в других фирмах, заработной платы на конкурентном рабочем месте (в дополнительной профессии), а также от уровня безработицы в текущей профгруппе и в конкурентной профгруппе. При высокой текущей заработной плате работники будут прилагать больше усилий на занимаемом рабочем месте и не стремиться перейти в другую фирму. Вместе с тем если условия труда и заработная плата в конкурентной профгруппе окажутся более предпочтительными и высокими, то работник будет прилагать меньше усилий на текущем рабочем месте и захочет покинуть данную фирму. Но если безработица в текущей профгруппе ниже, чем безработица в конкурентной профгруппе, работник будет прилагать большие 
усилия на текущем рабочем месте. Таким образом, обобщенная функция усилий и ее условия примут вид

$$
e=e\left(w, w_{a}, w_{k}, u, u_{k}\right), \frac{\partial e(\cdot)}{\partial w}>0, \frac{\partial e(\cdot)}{\partial w_{a}}<0, \frac{\partial e(\cdot)}{\partial w_{k}}<0, \frac{\partial e(\cdot)}{\partial u}>0, \frac{\partial e(\cdot)}{\partial u_{k}}>0
$$

где $w_{a}$ - заработная плата в других фирмах по аналогичной профгруппе; $w_{k}$ - заработная плата в конкурирующей профгруппе или заработная плата в той профгруппе, в которую с минимальными затратами может перейти данный работник; $u$ - безработица в текущей профгруппе; $u_{k}$ - безработица в конкурирующей профгруппе.

Работники стремятся максимизировать индивидуальную функцию полезности потребления, в которой потребление приравнивается к индивидуальному доходу работника или заработной плате. В некотором смысле повышение заработной платы должно приводить к увеличению полезности потребления, что придает особое значение выбору фирмами показателя заработной платы с точки зрения работника. Фирма может свободно выбирать уровень заработной платы при наличии безработных на рынке труда, а при нулевой безработице должна платить работникам не менее, чем другие фирмы.

Если фирма не ограничена в своем выборе, то условия первого порядка для $L$ и $w$ с учетом алгебраических преобразований примут вид

$$
\begin{gathered}
F^{\prime}\left(e\left(w, w_{a}, w_{k}, u, u_{k}\right) L\right)=\frac{w}{e\left(w, w_{a}, w_{k}, u, u_{k}\right)}, \\
\frac{w e_{1}^{\prime}\left(w, w_{a}, w_{k}, u, u_{k}\right)}{e\left(w, w_{a}, w_{k}, u, u_{k}\right)}=1 .
\end{gathered}
$$

Уравнение (5) представляет собой условие Солоу, согласно которому эластичность усилий по заработной плате равна единице. Это условие первого порядка описывает проблему выбора ставки текущей заработной платы и позволяет минимизировать издержки эффективного труда $w / e$. Если заработная плата удовлетворяет этому условию, то ее следует считать эффективной заработной платой. Для нахождения эффективной заработной платы в условиях профессиональной мобильности и конкуренции между работниками, находящимися в разных профессиональных группах, предположим, что функция $e(\cdot)$ такова, что при фиксированных $w_{a}, w_{k}, u$ и $u_{k}$ существует единственное оптимальное $w$. Значение $w$ определяет поведение и выбор работника и фирмы.

В условиях возможной конкуренции между профгруппами предположим, что функция усилий работника представляет следующую систему: 


$$
\begin{aligned}
& e=\left\{\begin{array}{l}
\left(\frac{w-\chi_{a}}{\chi_{a}}\right)^{\mathrm{z}}\left(\frac{w-\chi_{k}}{\chi_{k}}\right)^{1-z}, \text { при } w>\chi_{a} \text { и } w>\chi_{k}, \\
0 \text { в остальных случаях, }
\end{array}\right. \\
& \chi_{a}=(1-b u) w_{a}, \chi_{k}=\left(1-b_{k} u_{k}\right) w_{k},
\end{aligned}
$$

где $0<z<1$ представляет собой предпочтение работника относительно определенной профгруппы. Чем ближе $z$ к единице, тем предпочтительнее текущая профессия и профгруппа. $b>0$ и $b_{k}>0$ представляют собой параметры, учитывающие индивидуальное восприятие безработицы соответственно в текущей профессии и в конкурентной профессии. Если значение данных параметров больше единицы, то это означает, что работники придают больший вес безработице, нежели оплате труда, и наоборот. Параметр $\chi_{a}$ характеризует условия на рынке труда в текущей профгруппе или аналогичной профессии, а соответственно параметр $\chi_{k}$ характеризует условия труда в конкурентной профгруппе и в дополнительной профессии. Из выражения (6) видно, что текущая заработная плата, превышающая условия труда как в своей профгруппе, так и в конкурирующей профгруппе, приводит к увеличению усилий менее чем пропорционально с ростом $w-\chi_{a}$ и (или) $w-\chi_{k}$.

Дифференцирование функции усилий (6) показывает, что условие (5) после алгебраических преобразований примет вид

$$
w=\frac{\chi_{a} \chi_{k}}{z \chi_{a}+(1-z) \chi_{k}} .
$$

А с учетом (7) получим

$$
w=\frac{(1-b u) w_{a}\left(1-b_{k} u_{k}\right) w_{k}}{z(1-b u) w_{a}+(1-z)\left(1-b_{k} u_{k}\right) w_{k}} .
$$

Из уравнений (8) и (9) следует, что фирма должна платить работнику эффективную заработную плату, ориентируясь на оплату труда других фирм, как в данной профессии, так и в конкурирующих профессиях, т.е. работники, обладающие большей совокупностью компетенций, должны получать относительно пропорционально большую заработную плату. На практике оценка заработной платы фирмами ограничивается лишь одной профессией, без учета прочих способностей работников по занимаемой ими должности [23]. В случае, если способности работника по текущей и конкурентной профессии являются комплементарными, фирмам следует учитывать это в заработной плате.

Чтобы глубже понять взаимосвязь параметров текущей, аналогичной и конкурентной профессий, уравнение (9) следует преобразовать: 


$$
w=\frac{(1-b u) w_{a}}{z \cdot\left(\frac{(1-b u) w_{a}}{\left(1-b_{k} u_{k}\right) w_{k}}-1\right)+1}
$$

и ввести новое обозначение:

$$
\delta=\frac{1}{z \cdot\left(\frac{(1-b u) w_{a}}{\left(1-b_{k} u_{k}\right) w_{k}}-1\right)+1}
$$

тогда

$$
w=\delta \cdot(1-b u) w_{a} .
$$

Параметр $\delta$ представляет собой премию. С ростом заработной платы в конкурентной профессии $\left(w_{k}\right)$ параметр $\delta$ будет увеличиваться, т.е. фирма будет предлагать премию своим работникам к заработной плате, чтобы удержать их на текущих рабочих местах. Если другие фирмы будут поднимать заработную плату в данной профгруппе, то и заработная плата на текущем рабочем месте будет тоже увеличиваться, но медленнее, чем в целом по профгруппе, так как параметр, учитывающий премии $(\delta)$, будет уменьшаться, ослабляя общий рост текущего заработка. В данном случае тенденция роста будет совпадать с ожиданиями работников и желание сменить профессию у них будет ослаблено. При этом чем интенсивнее растут заработные платы на аналогичных рабочих местах, тем медленнее будет расти заработная плата на текущем рабочем месте, компенсируясь в основном имплицитными ожиданиями.

Исходя из функции усилий при фиксированных ее переменных внутри текущей профгруппы, должно выполняться равенство $w=w_{a}$, характеризующее равновесие внутри текущей группы. В таком случае фирма должна учитывать, что

$$
w=\frac{w_{k}\left(1-b_{k} u_{k}\right)(z-b u)}{z(1-b u)},
$$

т.е. текущая заработная плата будет полностью зависеть от ее размера в конкурентной профгруппе. Но если текущая заработная плата выше, чем у других фирм, и даже выше, чем в конкурентной профгруппе, то работник будет прилагать максимум усилий и не думать о смене места работы. И лишь в случае если $w_{a}$ или $w_{k}$ больше текущего заработка, усилия работника будут снижаться согласно (6).

Таким образом, если $w=w_{a}$, т.е. наблюдается равновесие в текущей профгруппе, то согласно (13) работник сравнивает свою заработную плату с 
$w_{k}$, учитывая при этом предпочтение профессий и условия на рынке труда в текущей и конкурентной профгруппах.

Для того чтобы работник отдавал полностью предпочтение текущей профгруппе при условии $w_{k} \geq w_{a} \geq w$, т.е. при $z \rightarrow 1$, и не ушел из фирмы, его заработная плата должна быть: $w=w_{k}\left(1-b_{k} u_{k}\right)$. То есть текущая зарплата должна учитывать оплату труда в конкурентной профессии, но если безработица в конкурентной профессии будет расти, то усилия работника в текущей профессии будут повышаться, а текущую заработную плату (w) фирма будет снижать до момента, пока заработная плата в текущей профгруппе не сравняется с заработной платой в конкурентной профгруппе, т.е. $w_{k}=w_{a}$.

Так же если $\chi_{a}=\chi_{k}$ и $w_{a}=w_{k}$, то выбор оплаты труда фирмой и рабочего места работником будет полностью зависеть от восприятия безработицы и самой безработицы в каждой из профессий. Если $u_{k}>u, b>b_{k}$ и, возможно, $z>0,5$ означает, что усилия работника в текущей профессии будут повышаться, так как работника будет смущать высокая безработица в конкурентной группе при условии большей важности безработицы в текущей группе. Это следует также из равновесных условий, когда $w=w_{a}=w_{k}$ и $u=u_{k}$, а усилия равны

$$
e=\frac{\frac{z}{1-z} \cdot \frac{b_{k}}{b}+1}{\frac{b_{k}}{b}+1}
$$

Из выражения (14) следует, что в условиях, когда заработная плата одинакова как на текущем рабочем месте, так и на конкурирующем, усилия работника будут полностью определяться отношением предпочтения профессий $(z /(1-z))$ и «страхом» безработицы при смене профессии $\left(b_{k} / b\right)$. С ростом предпочтения текущей профессии (z) усилия работника будут расти, при этом предпочтение обычно отдается профессии с максимальной оплатой равного количества труда $(L)$. В условиях осмысления работником возможности ухода в другую профессию или даже при поиске другой работы у работника возможен рост восприятия безработицы в конкурентной профгруппе или снижение восприятия безработицы в текущей профгруппе при постоянном предпочтении профессий $(z)$, при этом усилия работника на текущем рабочем месте начнут снижаться согласно выражению (14). Если $z=0,5$ и $b=b_{k}$, усилия будут равны единице $e\left(w, w_{a}, w_{k}, u, u_{k}\right)=1$, тогда наблюдается ситуация, когда работнику в равной мере симпатизирует и текущая, и конкурентная профессия, а усилия находятся на уровне, обеспечивающем равенство предельного продукта труда реальной заработной плате (согласно формуле (4)), что характеризует рынок труда как совершенно конкурентный. Но возможна эта ситуация лишь при равенстве ставок заработных плат текущей, в других фирмах и конкурентной профессии одной единой равновесной ставке 
оплаты труда $\left(w^{*}\right)$. Равновесная заработная плата с учетом равенств ставок зарплаты будет находиться по формуле

$$
w^{*}=F^{\prime}\left(e\left(w, w_{a}, w_{k}, u, u_{k}\right) L\right) e\left(w, w_{a}, w_{k}, u, u_{k}\right) .
$$

В ситуации, когда увольнение работника или его уход, смена работником места работы связаны с определенными издержками или «трениями», по П. Даймонду, К. Писсаридесу и Д. Мортенсену, а безработица в текущей профгруппе минимальна или практически отсутствует, то работнику лучше придерживаться стратегии повышения усилий труда, а фирме при этом нужно постараться повысить заработную плату, чтобы не столкнуться с дефицитом рабочей силы по текущей профессии. То есть «трения», вызванные сменой рабочего места и обусловленные потерей времени на поиски работы, скорее всего будут смещать приоритет в профгруппах в сторону текущей профгруппы, т.е. повышая $z>0,5$. В пользу роста $Z$ говорят также такие факты, как требуемое обновление навыков в конкурентной профгруппе, повышение квалификации и связанные с ним возможные затраты и т.д. Таким образом, в описанных условиях строгое равенство $w^{*}=w=w_{a}=w_{k}$ не совсем корректно выполняется, что может говорить о неполной номинальной подстройке в заработных платах, согласуясь с теорией Р. Лукаса [24]. Но если конкурирующая фирма берет на себя затраты по адаптации работника в его профессии по специальности диплома или даже переподготовку работника, то значение $z$ будет скорее снижаться, приводя работника к мысли о смене профессии и рабочего места. Если же работник вынужден сам оплачивать переподготовку и адаптацию на новом месте, то его инвестиции в свой человеческий капитал должны быть учтены в будущей заработной плате в конкурентной профгруппе. То есть суммарные инвестиции в текущем периоде должны окупиться будущей заработной платой. Это условие соответствует выражению

$$
\sum w L+\sum(1+r)^{t} I=\sum w_{k} L_{k}
$$

где $I$ - суммарные инвестиции в переподготовку или получение новой профессии; $r$ - ставка процента; $t$ - период времени; $L, L_{k}$ - количество нанимаемого труда соответственно в текущей и конкурентной профгруппах.

Выражая из (16) заработную плату в конкурентной профгруппе, в общем случае получим

$$
w_{k}=\frac{(1+r) I}{L_{k}}+\frac{w L}{L_{k}} \text {, }
$$

что свидетельствует о значительном влиянии на предпочтение профессий $(z)$ размера заработной платы по конкурентной профессии и условий, определяющих, на кого ложатся инвестиции и как в итоге эти инвестиции окупятся. Формула (17) показывает, что размер инвестиций на единицу труда дол- 
жен быть дисконтирован, так как у работника существует альтернативный выбор инвестировать или сберегать, и если бы он выбрал сбережение, то его доход составил бы $(1+r)^{t} I / L_{k}$ в расчете на единицу труда, при $I=S$, где $S$ - сбережение [25]. Если фирмы ощущают дефицит в рабочей силе по определенной профессии, т.е. безработица в данной профгруппе минимальна или практически отсутствует, то они скорее всего будут брать на себя бремя инвестиций в человеческий капитал, чтобы расширить количество вовлеченных в данную профессию работников. В этом случае будет наблюдаться приток в конкурирующую профессию при уменьшении $Z$ и увеличении ставки оплаты труда в конкурентной профессии. Вместе с этим ставки оплаты труда в текущей профессии также должны вырасти согласно равенству (13), что будет способствовать росту усилий как в текущей, так и в конкурирующей профгруппе.

Уравнение (17) также может характеризоваться более сложной системой компенсации. Нефинансовые услуги фирмы работникам, компенсирующие часть их обязательных затрат (например, питание на работе, детские сады для детей работников и т.д.), могут быть менее затратными способами получения выгод от повышенного вознаграждения, состоящего не только из заработной платы в ее денежном выражении. Часть затрат на такие услуги может составлять дополнительную прибавку к заработной плате работников и, возможно, цениться ими больше, принося комфорт и не отрывая лишний раз от работы. Существенные выгоды от такой разнообразной и достаточно сложной системы компенсации будут наблюдаться в основном в корпоративном секторе экономики крупных и средних фирм.

Для соблюдения (15) в условиях равновесия рынка труда необходимо определить параметры безработицы в текущей и конкурирующей группах профессий. Безработица в текущей группе будет равна

$$
u=\frac{\frac{z}{b}}{u_{k}-\frac{(1-z)}{b_{k}}}
$$

Из выражения (18) следует, что с увеличением безработицы в конкурентной профгруппе $\left(u_{k}\right)$ безработица в текущей профгруппе $(u)$ будет снижаться, таким образом будет наблюдаться переток работников из конкурентной группы в текущую профгруппу. Основными параметрами, определяющими безработицу в текущей профгруппе, являются: безработица в конкурентной профгруппе, значение восприятия работником безработицы в текущей группе $(b)$ и предпочтение текущей профессии $(z)$. При этом важно отметить, что значение восприятия работником безработицы в текущей профессии $(b)$ взаимосвязано обратно пропорционально с безработицей в текущей профессии $(u)$, т.е. чем меньше безработица в текущей профгруппе, тем больше ее 
восприятие работником. Таким образом, знаменатель в формуле (18) является величиной постоянной и $u_{k}>\frac{(1-z)}{b_{k}}$, при $b_{k}>1$.

В случае определения безработицы в конкурентной профгруппе получим

$$
u_{k}=\frac{\frac{1-z}{b_{k}}}{1-\frac{z}{b u}} .
$$

Таким образом, на безработицу в конкурентной профгруппе влияют: предпочтение профессий $(z)$, значение восприятия работником безработицы в конкурирующей профгруппе $\left(b_{k}\right)$, а также безработица в текущей профессии $(u)$. Здесь также наблюдается обратно пропорциональная взаимосвязь восприятия безработицы в конкурентной профессии и значения самой безработицы в конкурентной профессии. Графически взаимосвязь безработицы и ее восприятия работниками представлена на рис. 1 .

Взаимосвязь между безработицей и ее восприятием работником подтверждается также формулой (9), если ее преобразовать как

$$
w=\frac{1}{\frac{1-z}{(1-b u) w_{a}}+\frac{z}{\left(1-b_{k} u_{k}\right) w_{k}}} .
$$

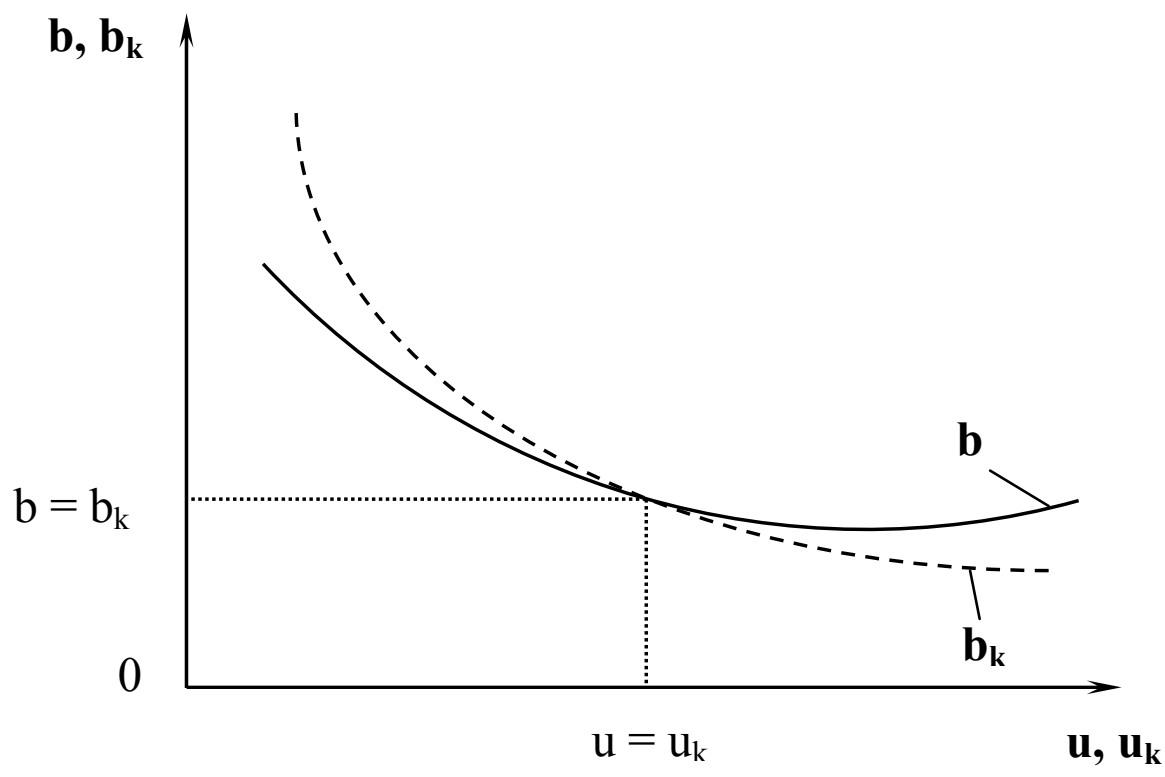

Рис. 1. Взаимосвязь безработицы и ее восприятия работником 
Из выражения (20) следует, что с увеличением безработицы в текущей профессии $(u)$ заработная плата $\left(w_{a}\right)$ должна увеличиваться таким образом, что $(1-b u) w_{a}$ также увеличивается, и это ведет к увеличению заработной платы на текущем рабочем месте $(w)$, что подтверждается законом спроса и предложения на рабочую силу. Так как часть фирм платят эффективную заработную плату выше среднерыночной, то на рынке труда существует безработица, т.е. больше людей хотят предложить свою рабочую силу по большей ставке оплаты труда. Увеличение занятости или, что то же самое, снижение безработицы предполагает движение вдоль кривой спроса на труд в сторону увеличения объема труда, а это, в свою очередь, приводит к снижению ставки оплаты труда во вновь заключаемых контрактах до равновесного более низкого уровня. Что касается $b_{k} u_{k}$, то это произведение будет представлять примерно постоянную величину, так как увеличение безработицы в конкурентной профессии будет компенсироваться снижением значимости восприятия этой же безработицы согласно рис. 1.

Если в условиях равновесия рынка труда наблюдается равновесие в уровнях безработицы $\left(u=u_{k}\right)$, то работник при выборе профгруппы будет ориентироваться только на индивидуальные субъективные предпочтения:

$$
u=\frac{z}{b}+\frac{1-z}{b_{k}}
$$

Или если значения безработицы в конкурентной и текущей профгруппах равны и значения восприятия безработицы тоже равны, (т.е. $u=u_{k}, b=b_{k}$ ), что может наблюдаться, когда работник, работая на текущем рабочем месте, подыскивает себе новое рабочее место в конкурентной профгруппе или он работает на двух работах на полставки, выбирая, в какой профессии остаться, то в таких условиях равновесия безработица составит

$$
u=1 / b .
$$

Это подтверждает выводы рис. 1 и взаимосвязь безработицы и ее восприятия работником.

Представленная модель эффективной заработной платы в условиях профессиональной мобильности работников позволяет учитывать сложную систему индивидуальных решений работников и фирм на рынке труда. Стремление фирм и индивидов к максимизации своих целевых функций приводит к профессиональной мобильности работников. Основным показателем в принятии решений является ставка эффективной заработной платы, которая должна учитывать всю систему издержек по переходу в новую или дополнительную профессию, а фирмам позволит повысить усилия работников и производительность труда, что в итоге максимизирует их прибыль. Эффективная заработная плата позволит фирмам привлекать наиболее компетентных работников, отличающихся высокими как наблюдаемыми, так и ненаблюдаемыми качествами, знаниями и компетенциями, а также снизит тенденции к 
уклонению работников от обязанностей в условиях отсутствия совершенного мониторинга их деятельности.

\section{Литература}

1. Кернс Дж.Э. Логический метод политической экономии. М.: Книжный дом «Либроком», 2012.

2. Милль Дж.С. Основания политической экономии с некоторыми применениями к общественной философии. Киев; Харьков: Южно-русское книгоиздательство Ф.А. Іогансона, 1896.

3. Dunlop T.J. Industrial Relations Systems. New York: Henry Holt, 1958.

4. Lewis G.H. Union Relative Wage Effects: A Survey. Chicago: University of Chicago Press, 1986.

5. Hirsch B.T., Addison J.T. The Economic Analysis of Unions: New Approaches and Evidence. Boston: Allen \& Unwin, 1986.

6. Kerr $C$. The Balkanization of Labor Markets. In Labor Mobility and Economic Opportunity. Cambridge, MA: Technology Press of MIT, 1954.

7. Ross A.M. Do We Have a New Industrial Feudalism? // American Economic Review. 1958. № 48 (5)

8. Reynolds L.G. The Structure of Labor Markets: Wages and Labor Mobility in Theory and Practice. New York: Harper, 1951.

9. Blau F.D., Kahn L.M. Gender Differences in Pay // Journal of Economic Perspectives. 2000. № 14 (4).

10. Doeringer P.B., Piore M.J. Internal Labor Markets and Manpower Analysis. Lexington, MA: Heath. 1971.

11. Darity W.A., Mason P.L. Evidence on Discrimination in Employment: Codes of Color, Codes of Gender // Journal of Economic Perspectives. 1998. № 12 (2).

12. Williamson O.E., Wachter M., Harris J. Understanding the Employment Relation: The Analysis of Idiosyncratic Exchange // Bell Journal of Economics. 1975. № 6.

13. Akerlof G. Gift Exchange and Efficiency Wage Theory: Four Views // American Economic Review Proceedings. 1984. № 74.

14. Katz L.F Efficiency Wage Theories: A Partial Evaluation // NBER Macroeconomics Annual. 1986. Vol. 1.

15. Summers L.H. Relative Wages, Efficiency Wages, and Keynesian Unemployment // American Economic Review. 1988. Vol. 78. Vol. 74

16. Yellen J.L. Efficiency Wage Models of Unemployment // American Economic Review. 1984. Vol. 1.

17. Solow R. Another Possible Source of Wage Stickiness // Journal of Macroeconomics. 1979.

18. Lang K., Leonard J. Labor Market Structure, Wages, and Unemployment. In Unemployment and the Structure of Labor Markets. New York: Blackwell. 1987.

19. Faure E. et al. Learning to Be: The World of Education Today and Tomorrow, Report of the Edgar Faure Commission. Paris: UNESCO, 1972.

20. Delors J. et al. Learning: The Treasure Within / Report to UNESCO of the International Commission on Education for the Twenty-first Century. Paris: UNESCO, 1996.

21. Смолякова T. Что показал опрос Росстата об отношении россиян к труду // Российская газета. М.: «Редакция «Российская газета». - 13.08.2012 [Электронный ресурc]. URL: http://www.rg.ru/2012/08/13/laykam.html «Российская газета - Экономика». Загл. с экрана.

22. Romer D. Advanced Macroeconomics. New York: McGraw-Hill Companies, Inc, 2012.

23. Мачин К.A. Экономический анализ модели эффективной заработной платы в условиях профессиональной мобильности // Экономический анализ: теория и практика. 2015. № 3 (402).

24. Lucas R. Models of Business Cycles. Oxford: Basil Blackwell, 1987.

25. Мачин К.A. Эффективная заработная плата в условиях перекрестной конкуренции между профессиональными группами работников // Вестник алтайской науки. 2014. № 4 (22). 
K.A. Machin Altai State Technical University, Barnaul, Russia. E-mail: matschin@yandex.ru LIFELONG LEARNING, PROFESSIONAL MOBILITY AND EFFICIENCY WAGES IN THE LABOUR MARKET

Keywords: lifelong learning, professional mobility, effective wages, non-competitive group, efforts of the worker, efficiency of labor, unemployment.

The modern dynamically developing society imposes new demands on higher abilities and efforts of employees. This determines the points of contact between the economic interests of workers and employers. Companies are maximizing their profits, and workers are maximizing their individual utilities. The clash of these goals is effectively regulated by the market mechanism based on the formation of an efficiency wages. Making decisions about the amount of wages in terms of the absolute impossibility of monitoring the activities and results of workers' operations should be carried out on the principles of the efficiency wages theories. If an employee has a spectrum of competencies in several professions, his effective wages should be taken into consideration, otherwise he may go to another company which offers a greater salary based on the whole range of his competence. In terms of occupational mobility, the company should be fully informed about the professional competence of its employees and should build up an individual remuneration system taking into account the full range of his competence. The main purpose of the author's research is the formation of occupational mobility's economic mechanism on the basis of modeling decisions on the effective wage. Formation of an effective wage by a representative firm should consider all employee's abilities to maintain his efforts on high-level and eliminate shirking. The growth of the current employee's salary must always take into account its amount in the same occupational group at other enterprises and wage in that occupational group to which the worker can escape. If the company sets effective wages for its employees, the labor of these workers will also be effective. The results of the survey will be useful to economists of HR departments for establishing effective system of staff remuneration.

\section{References}

1. Kerns Dzh. Je. Logicheskij metod politicheskoj jekonomii [Character and Logical Method of Political Economy]. Moscow, Knizhnyj dom «Librokom», 2012.

2. Mill' Dzh. S. Osnovanija politicheskoj jekonomii s nekotorymi primenenijami k obshhestvennoj filosofii [Foundations of Political Economy with some applications to social philosophy]. Kiev Har'kov, Juzhno-russkoe knigoizdatel'stvo F.A. Iogansona, 1896.

3. Dunlop T. J. Industrial Relations Systems. New York, Henry Holt, 1958.

4. Lewis G. H. Union Relative Wage Effects: A Survey. Chicago, University of Chicago Press, 1986.

5. Hirsch B. T., Addison J. T. The Economic Analysis of Unions: New Approaches and Evidence. Boston, Allen \& Unwin, 1986.

6. Kerr C. The Balkanization of Labor Markets. In Labor Mobility and Economic Opportunity. Cambridge, MA: Technology Press of MIT, 1954.

7. Ross A. M. Do We Have a New Industrial Feudalism? American Economic Review, 1958, № 48 (5).

8. Reynolds L. G. The Structure of Labor Markets: Wages and Labor Mobility in Theory and Practice. New York, Harper, 1951.

9. Blau F. D., Kahn L. M. Gender Differences in Pay. Journal of Economic Perspectives, 2000, № 14 (4).

10. Doeringer P. B., Piore M. J. Internal Labor Markets and Manpower Analysis. Lexington, MA, Heath, 1971.

11. Darity W. A., Mason P. L. Evidence on Discrimination in Employment: Codes of Color, Codes of Gender. Journal of Economic Perspectives, 1998, № 12 (2).

12. Williamson O. E., Wachter M., Harris J. Understanding the Employment Relation: The Analysis of Idiosyncratic Exchange. Bell Journal of Economics, 1975, № 6.

13. Akerlof G. Gift Exchange and Efficiency Wage Theory: Four Views. American Economic Review Proceedings, 1984, № 74.

14. Katz L. F Efficiency Wage Theories: A Partial Evaluation. NBER Macroeconomics Annual, 1986, Vol. 1.

15. Summers L. H. Relative Wages, Efficiency Wages, and Keynesian Unemployment. American Economic Review, 1988, Vol. 78. 

Vol. 74

16. Yellen J. L. Efficiency Wage Models of Unemployment. American Economic Review, 1984,

17. Solow R. Another Possible Source of Wage Stickiness. Journal of Macroeconomics, 1979, Vol. 1.

18. Lang K., Leonard J. Labor Market Structure, Wages, and Unemployment. In Unemployment and the Structure of Labor Markets. New York, Blackwell, 1987.

19. Faure E. et al Learning to Be: The World of Education Today and Tomorrow, Report of the Edgar Faure Commission. Paris, UNESCO, 1972.

20. Delors J. et al Learning: The Treasure Within / Report to UNESCO of the International Commission on Education for the Twenty-first Century. Paris, UNESCO, 1996.

21. Smoljakova T. Chto pokazal opros Rosstata ob otnoshenii rossijan k trudu [What Rosstat survey showed the attitude of Russians to work]. Rossijskaja gazeta, Moscow, «Editorial «Rossijskaja gazeta». 13.08.2012. Available at:http://www.rg.ru/2012/08/13/laykam.html (accessed 3 November 2015). (In Russian).

22. Romer D. Advanced Macroeconomics. New York, McGraw-Hill Companies, Inc, 2012.

23. Machin K. A. Jekonomicheskij analiz modeli jeffektivnoj zarabotnoj platy v uslovijah professional'noj mobil'nosti [The Economic analysis of models of an efficiency wages in the conditions of professional mobility]. Jekonomicheskij analiz: teorija i praktika, 2015, no. 3 (402).

24. Lucas R. Models of Business Cycles. Oxford, Basil Blackwell, 1987.

25. Machin K.A. Jeffektivnaja zarabotnaja plata $\mathrm{v}$ uslovijah perekrestnoj konkurencii mezhdu professional'nymi gruppami rabotnikov [Efficiency wages in a Cross-Competition between professional groups of workers]. Vestnik altajskoj nauki, 2014, no. 4 (22). 